\title{
Individual Moral Judgment and Cultural Ideologies
}

\author{
Darcia Narvaez \\ University of Minnesota, Twin Cities Campus
}

\author{
Irene Getz \\ Luther Seminary and \\ University of Minnesota, Twin Cities Campus
}

\author{
James R. Rest and Stephen J. Thoma \\ University of Minnesota, Twin Cities Campus
}

\begin{abstract}
Moral judgment cannot be reduced to cultural ideology, or vice versa. But when each construct is measured separately, then combined, the product predicts powerfully to moral thinking. In Study 1, 2 churches $(N=96)$ were selected for their differences on religious ideology, political identity, and moral judgment. By combining these 3 variables, a multiple correlation of .79 predicted to members' moral thinking (opinions on human rights issues). Study 2 replicated this finding in a secular sample, with the formula established in Study $1(R=.77)$. Individual conceptual development in moral judgment and socialization into cultural ideology co-occur, simultaneously and reciprocally, in parallel, and not serially. Individual development in moral judgment provides the epistemological categories for cultural ideology, which in turn influences the course of moral judgment, to produce moral thinking (e.g., opinions about abortion, free speech).
\end{abstract}

Theories of moral development typically invoke two processes to explain change over time: (a) socialization of the individual into cultural ideology and (b) the individual's cognitive construction of social and moral meaning. Theorists differ in terms of emphasizing one process or the other and in terms of which process is assumed to be dominant at one period of time. The concepts of autonomy and heteronomy are used to refer, respectively, to the individual, cognitive-constructionist, agentic aspect of morality and to the external, shared-group, conforming aspect. Autonomy and heteronomy are the yin and the yang of moral theorists. On the one hand, cognitive-developmental theories, centering on the construct of moral judgment, emphasize the development of autonomy. On the other hand, social learning theories and cultural psychology theories, centering on cultural transmission, emphasize heteronomy. Moreover, Piaget (1932/1965) postulated that development consists of moving from heteronomy to autonomy; Kohlberg

Darcia Narvaez and James R. Rest, Department of Educational Psychology and Center for the Study of Ethical Development, University of Minnesota, Twin Cities Campus; Irene Getz, Luther Seminary, St. Paul, Minnesota, and Center for the Study of Ethical Development, University of Minnesota, Twin Cities Campus; Stephen J. Thoma, Center for the Study of Ethical Development, University of Minnesota, Twin Cities Campus.

Stephen J. Thoma is now at the Department of Human Development, University of Alabama.

Part of this study is based on a doctoral dissertation written by Irene Getz in fulfillment of degree requirements at the University of Minnesota, Twin Cities Campus.

Correspondence concerning this article should be addressed to Darcia Narvaez, Department of Educational Psychology, University of Minnesota, Twin Cities Campus, 206 Burton Hall, 178 Pillsbury Drive, SE, Minneapolis, Minnesota 55455. Electronic mail may be sent to narvaez@tc.umn.edu.
(1969) postulated oscillation between heteronomy and autonomy within each stage-as A and B substages. In this article, we take the view that both processes are involved in the formation of moral thinking but that they are simultaneous, parallel, and reciprocal processes.

We use the term moral thinking to refer to people's judgments about right and wrong and the rationale behind such thinking. Moral thinking is meant to be broader than moral judgment in that the moral judgment construct refers more narrowly to the cognitive construction of basic epistemological categories (e.g., justice, duty, legitimate authorities, and rights). In contrast, moral thinking-as we use the term-refers to a person's views on such issues as abortion, rights of homosexual individuals, religion in public schools, women's roles, and euthanasia. Cultural ideology is another basic process in the formation of moral thinking and refers to values, norms, and standards that exist independently of a single person and that are shared by a group as part of its mutual culture. Our position is that both moral judgment and cultural ideology contribute significantly and uniquely to moral thinking. We have in mind a two-process, parallel theory for moral thinking, somewhat like the two-process, parallel theory of Kintsch and van Dijk (1978) for text comprehension-that is, the production of moral thinking involves two processes occurring simultaneously and reciprocally, not serially or at different times.

A good place to examine differences in moral thinking is in the clash of views on public policy issues described by Hunter (1991) in his book entitled Culture Wars: The Struggle to Define America. The moral issues at stake are abortion, rights of homosexual individuals, religion in public schools, and so forth. Hunter described the activities of antagonistic pressure groups: lobbying in political parties and legislatures against each other, sending out mailings against each other, participating in hostile radio talk shows, splitting church denominations, and sponsoring public 
demonstrations. Hunter called the polar opposites "Orthodoxy" and "Progressivism." Orthodoxy locates moral authority in traditional, transcendent religion (Hunter, 1991, p. 44), whereas Progressivism locates moral authority in "the spirit of the modern age, a spirit of rationalism and subjectivism" (pp. 44-45). The split between Orthodoxy and Progressivism frustrates the attempt to find consensus on many issues of public policy in the United States. In similar terms, Marty and Appleby (1993) described the international aspect of this polarization, stating that the greatest ideological clash since the cessation of the Cold War is between Fundamentalism and Secular Modernism. In a series of edited volumes on countries throughout the world, they described "sectarian strife and violent ethnic particularisms, to skirmishes spilling over into border disputes, civil wars, and battles of secession" (Marty \& Appleby, 1993, p. 1). Thus, the Orthodox-Progressive clash in worldview is a significant phenomenon to investigate in the study of moral thinking.

A great deal of effort has been devoted to treating the two processes (moral judgment and cultural ideology) as rival explanations, reducing one construct to the other construct. For instance, Emler, Resnick, and Malone (1983) contended that the Kohlbergian scheme of moral stages-and the Defining Issues Test (DIT) in particular-is really a manifestation of liberal-conservative political ideology. Emler et al. stated,

Moral reasoning and political attitudes are by and large one and the same thing... . We believe that individual differences in moral reasoning among adults-and in particular those corresponding to the conventional-principled distinction-are interpretable as variations on a dimension of political-moral ideology and not as variations on a cognitive-developmental dimension. (pp. 1073-1075)

Opposing the reduction of DIT scores to political attitudes, as the above quote suggests, a recent book by Rest, Narvaez, Bebeau, and Thoma (1999; shorter treatments are given in Rest, Thoma, \& Edwards, 1997; Rest, Thoma, Narvaez, \& Bebeau, 1997) argues for a cognitive-developmental interpretation of Kohlbergian theory and the DIT. Briefly, the evidence consists of the following seven types of studies (for which over 400 published articles are cited): (a) discrimination of age, education, and expert groups; (b) longitudinal studies; (c) correlation with moral comprehension, cognitive capacity in moral thinking, and other cognitive-developmental measures; (d) pre- and posttest gains in moral intervention studies; (e) links to behavior and real-life decision making; (f) predictability to political attitudes and political choice; and (g) reliability. These studies argue that, in accord with Kohlberg's (1984) theory, the DIT shows individual development in adolescence and adulthood, from conventional to postconventional thinking. In the present article, we assumed that Kohlberg's theory about conventional thinking developing into postconventional thinking is a valid characterization of moral judgment development and that the DIT is a valid measure of moral judgment development. However, we relied on previous studies to make this case.

We supposed that both moral judgment and cultural ideology each provide separate information that does not reduce to the other and that moral thinking is produced by the simultaneous and reciprocal interaction of these processes, acting in parallel, not serially. We supposed that each individual struggles to construct meaning of the social world (as measured by the moral judgment construct). We also supposed that cultural ideology has a devel- opmental influence by emphasizing certain social phenomena; interpreting features of the social environment in certain ways; reinforcing certain group practices that organize social life and activity; and affording certain tools, instruments, and roles. Each person does not invent culture anew. However-and this is our main point-the acquisition of cultural ideology is conditioned by what makes sense to the individual. Individual cognitive development provides the conceptual bedrock for certain ideologies (bedrock in the sense of providing the basic epistemological categories by which to interpret cultural ideologies). In turn, cultural ideology affects the course of moral judgment. The question, we believe, is not whether individual moral judgment or group-based cultural ideology determines moral thinking but rather how they interrelate. Our strategy was to show that when measures of cultural ideology and moral judgment are separately measured and then combined, the combination predicts more powerfully to moral thinking than does either one alone. Before moving on to the empirical study, some comment should be made about how DIT research is both similar to and different from the classic Kohlbergian theory (for a more detailed discussion, see Rest et al., 1999, chap. 2). DIT research supposes-along with classic Kohlbergian theory-that the major developmental shift during adolescence and adulthood is from conventional to postconventional moral thinking. We describe development in terms of a shift from the schema of maintaining norms (largely Kohlberg's law-and-order, Stage 4, orientation) to the postconventional schema (largely Kohlberg's Stages 5 and 6). We depict development in terms of the individual's conceptualization of the moral basis of societal cooperation (how it is possible to organize cooperation on a societywide basis, especially when the participants relate to each other not on a personal, face-to-face basis but through social roles, institutional structures, and law). The maintaining-norms schema is defined in terms of respecting established social practices and existing authorities. We define postconventional schema in terms of shareable ideals for organizing society, subject to public scrutiny and debate. Different from Kohlberg, our definition of postconventionality is not partial to the specific moral philosophies of deontologists like Rawls (1993) or the European Liberal Enlightenment. Rather, our definition is broader (and looser) than Kohlberg's definition, including not only left-leaning philosophies (like Rawls, 1993) but also right-wing communitarian philosophers (like Sandel, 1982, and Walzer, 1983) - and, in fact, most modern moral philosophies. We contend that concepts of fairness and justice of society are not the same as leftist liberal ideology. For instance, the left-wing political correctness of the 1980 s (Gross \& Levitt, 1994) has received a moral critique as well as right-wing conservative political ideology (Haan, Smith, \& Block, 1968). The theoretical possibility that postconventional reasoning can critique injustices of both the political left and the political right implies that concepts of justice (moral judgment) are distinct from either political ideology of the left or the right; the empirical findings of this study argue for the nonequivalence of political ideology and moral judgment.

Having just said that moral judgment is not equivalent to leftwing political thinking, it is nevertheless true that right-wing political views are often associated with maintaining norms (Stage 4) and left-wing political views are associated with the postconventional schema (Stages 5 and 6). In fact, Rest et al. (1999) reviewed 37 statistically significant associations (usually correla- 
tions in the .40 to .60 range) between the DIT and liberal political attitudes. Note that our interpretation of these correlations is not that they show that moral judgment, political attitudes, and religious attitudes (and possibly other measures of ideology) all reduce to a single underlying factor of liberalism-conservatism. Liberalism-conservatism is not the ubiquitous counterpart in social cognition to the $g$ factor of intelligence tests. Our interpretation is not only to affirm some common covariation among these variables but also to assert their unique variance. First, the reason for the association between the DIT and political attitudes concerns the fact that the DIT postconventional $(P)$ score is sensitive to the shift between the maintaining-norms schema and the postconventional schema. This shift in conceptualizing society is accompanied by a shift in attitude toward authority (shifting from unquestioning support in the maintaining-norms schema to holding authorities accountable in the postconventional schema). There is also a shift in attitude toward the importance of maintaining established social norms and institutions (where the maintainingnorms schema supports all established norms but the postconventional schema supports only those practices that serve the community's shared ideals). In short, development in moral judgment is accompanied by shifts in political attitude. Most often, conservative positions are more supportive of authority and established practices, and postconventional thinkers find liberal political positions more congenial. However, the association between political attitudes and moral judgment is not an identity of constructs.

\section{Study 1: Church Sample}

We wanted to contrast Orthodox views with Progressive views. Therefore, like the studies of Ernsberger and Manaster (1981), Jelen (1989), and Jensen (1996, 1997), we looked to contrasting church congregations to find differences in worldview. We sought out congregations with contrasting reputations for liberalism or conservatism. Furthermore, we wanted to match the two congregations on as many demographic variables as possible so as to rule out explanations of differences being due to geographical region, occupation, age, education, race, sex, size of congregation, or neighborhood. Study 1 was of a pair of congregations in the metropolitan Twin Cities of Minnesota, in the same neighborhood, and of the same size (about 300 members): the liberal congregation being from the United Church of Christ (UCC) and the conservative congregation being an American Baptist congregation. Our first concern was to confirm that the "liberal" congregation was indeed liberal on our measures and that the "conservative" congregation was indeed conservative. Our next concern was to see how the ideology variables and the moral judgment variable could be combined to predict opinions on public policy issues.

\section{Method}

\section{Participants}

A random sample of 100 members from each congregation was mailed a set of questionnaires. Participants received $\$ 5$ for participating. Eightyseven Baptists and 80 UCC members returned the questionnaires. Of these, 50 Baptists and 46 UCC members had complete protocols on every variable and passed the consistency checks built into the DIT. ${ }^{1}$ Most of the participants who were dropped from the study were over 60 years old and were those whom we assumed had difficulties with the testing materials.

\section{Materials}

Major independent variables. Several measures of religious and political ideology were chosen to be the independent variables. Previous research has suggested that the instruments are robust: Brown and Lowe's (1951) Inventory of Religious Belief, Hoge's (1972) Intrinsic Religious Motivation Scale, and a measure of political conservatism-liberalism. In addition, the DIT was used as the measure of moral judgment. (The demographic variables were considered minor independent variables.)

Religious ideology. To measure religious fundamentalism, we chose to use Brown and Lowe's (1951) Inventory of Religious Belief. It is a 15-item measure that uses a 5-point Likert-type scale. Its items differentiate between those who believe and those who reject the literalness of Christian tenets. Example items are as follows: "I believe the Bible is the inspired Word of God" (a positively keyed item); "The Bible is full of errors, misconceptions and contradictions" (a negatively keyed item); "I believe Jesus was born of a Virgin"; and "I believe in the personal, visible return of Christ to earth." Scores on this instrument range from 15 to 75 . High scores indicate strong, literal Christian beliefs. Criterion group validity is high between more and less fundamentalistic church groups (Brown \& Lowe, 1951; Getz, 1984). Test-retest reliability has been reported to be in the upper $.70 \mathrm{~s}$. Spearman-Brown reliability has been found to be in the upper .80s (Brown \& Lowe, 1951). In this article, Cronbach's alpha was .95 for the entire group of 158 participants. This scale taps a key element of Orthodoxy, and the variable was labeled $F U N D A^{2}$ (Fundamentalism) in our reports of analyses.

Hoge's (1972) Intrinsic Religious Motivation Scale was chosen to determine whether religion was a primary source of direction and value in the lives of the participants. It consists of 10 items such as "My faith involves all of my life" and "In my life I experience the presence of the Divine." This instrument measures the degree to which participants have a theocentric interpretation of their experience and of the world. High scores indicate that religion is valued for its own sake and participants report that religious belief is central in their lives. Scores range from 10 to 40 . Studies with this measure have indicated a Kuder-Richardson reliability of .90 (Hoge, 1972). The Intrinsic Religious Motivation Scale is significantly negatively correlated with prejudice (Allport \& Ross, 1967). In this article, Cronbach's alpha for the entire group was .90 . We refer to these scale scores as THEO.

Political ideology. Participants were asked to identify their political identity on a 5-point political conservatism scale ranging from 1 (liberal) to 5 (conservative). Another approach to measuring political liberalismconservatism involves asking participants about a number of policy issues that are scored for advocating a liberal or a conservative position and then are summed across items to form a liberalism-conservatism score. However, we did not use this second approach because it was so similar to the dependent variable (Attitudes Toward Human Rights Inventory [ATHRI]) and because we thought that using political policy items as both indepen-

\footnotetext{
${ }^{1}$ Very stringent criteria were used for keeping participants in this study. Participants were eliminated for missing a single variable or for any inconsistencies. Rather than maximizing sample sizes with the usual methods for supplying missing data, we were more concerned with having confidence in the appraisals of the relative strength of the variables; therefore, we eliminated participants rather than tolerate any ambiguities in the data.

${ }^{2}$ Operationalized variables used in the statistical analyses are presented as abbreviations in all capital letters (e.g., FUNDA). Theoretical constructs are presented without capitalization (e.g., religious fundamentalism).
} 
dent and dependent variables would not produce interpretable and interesting findings. Furthermore, Emler et al. (1983) posed their challenge to the moral judgment construct in terms of political identity (the selfconscious affirmation about whether one is a liberal or a conservative). In addition, other researchers have used this 1-item self-report measure to assess political ideology (e.g., Jelen, 1991). We refer to this variable as POLCON (political conservatism, with high scores indicating conservatism).

Moral judgment. The DIT (Rest et al., 1999) is a paper-and-pencil test of moral judgment. It presents six dilemmas, each followed by a list of possible considerations in resolving the dilemma, which are rated and ranked for importance by the participant. The most widely used index of the DIT is the P score, representing the percentage of postconventional reasoning preferred by the respondent. Although the stages of moral thinking reflected on the DIT were inspired by Kohlberg's (1981) initial work, the DIT is not tied to a particular philosophical ethicist. The testretest reliability of the $\mathbf{P}$ score in heterogenous samples is generally in the high $.70 \mathrm{~s}$ and $.80 \mathrm{~s}$. Cronbach's alphas are usually in the high $.70 \mathrm{~s}$ and $.80 \mathrm{~s}$. In this article, Cronbach's alpha was .71 for the entire group.

Opinions about public policy issues. As the dependent variable, the measure of moral thinking - the ATHRI, constructed by Getz (1985)asked participants to agree or disagree (on a 5-point scale) with public policy issues such as abortion, euthanasia, rights of homosexual individuals, due-process rights of the accused, free speech, women's roles, and the role of religion in public schools. The ATHRI poses issues drawn from the American Constitution's Bill of Rights, similar to the large-scale studies of American attitudes about civil liberties by McClosky and Brill (1983). The ATHRI contains 40 items, 10 of which are platitudinous, "apple pie" statements of a general nature with which everyone tends to agree. Here are two examples of the platitudinous, noncontroversial items: "Freedom of speech should be a basic human right" and "Our nation should work toward liberty and justice for all." In contrast, 30 items are specific controversial applications of human rights, for example: "Books should be banned if they are written by people who have been involved in un-American activities" and "Laws should be passed to regulate the activities of religious cults that have come here from Asia." During initial validation, a pro-rights group (from an organization that had a reputation for backing civil liberties) and a selective-about-rights group (from a group with a reputation for selectively backing civil liberties) were enrolled in a pilot study $(N=101)$ with 112 controversial items (Getz, 1985). Thirty of the items that showed the strongest divergence between groups were selected for the final version of the questionnaire, along with 10 items that expressed platitudes with which there was not disagreement (see Getz, 1985, for additional details on the pilot study). Therefore, with the ATHRI, we had a total of 40 human rights issues that were related to civil libertarian issues. Scores range from 40 to 200. High scores represent advocacy of civil liberties. Cronbach's alpha was .93 for the entire group of participants in this article.

Demographic variables. Data were also collected on several demographic variables: education, sex, and occupation. We had originally selected the two congregations to match for these variables so that they would not be confounds in the analysis. Of these variables, education was the most serious possible confound because education is significantly and positively correlated with both civil liberty political attitudes (McClosky \& Brill, 1983) and the DIT (Rest, 1979). Therefore, we tried to control education so as to avoid the situation in which a positive relation of the DIT with public policy issues could be explained away as being due to education.

Education was rated on a 9-point scale as follows: $1=7$ years of elementary school or less, 2 = finished 8 th or 9 th grade, $3=$ some high school, $4=$ high school graduate, $5=$ some college or technical school, $6=$ college graduate, $7=$ same graduate school, $8=$ master's degree, and $9=$ doctorate degree. Participants gave education information about themselves and about the primary wage earner in their family, but the two were so highly related that we report results only from the participants' education information about themselves.

Finally, participants were asked to write down their occupation and that of the primary wage earner in their family. The Duncan Socio-Economic Index (Reiss, 1961) was used to analyze the responses concerning occupation. The Duncan index uses prestige ratings derived from public opinion polls (Haug, 1977). Scores range from 1 to 100, with higher numbers representing greater prestige. Again, we report results only from the participants' occupation because the two were so highly related.

\section{Procedure}

A questionnaire containing the various measures was randomly ordered for each participant so as to control for order effects. The questionnaires were then distributed by mail to a random sample of the members in each congregation.

\section{Results and Discussion}

\section{Demographics}

Basic demographic data for each group are listed in Table 1. The demographic variables for the two churches are given in the upper left portion of Table 1. Recall that our intention was to match the two congregations on these variables so that demographic variables would not confound the other analyses. As intended, the subsamples were well matched on occupation and sex. There were no significant differences between the church groups on occupational status. The only sex difference was that the women tended to have more education than the men in both congregations. Although the samples were nearly of equal size, there were more women in each group. However, there was a significant difference in average education between the two congregations; the more conservative Baptists reported a higher level of education for themselves and for the family breadwinner than did the members of the more liberal UCC congregation. This finding reverses the direction of the correlation that is usually found. In large-scale representative samples (e.g., McClosky \& Brill, 1983), education is positively correlated with liberalism. Because this sample was not a large-scale representative sample of the U.S. population, these education findings do not threaten the generalizations from representative samples. So as things turned out, our particular selection of groups overcompensated for education. In any case, a positive relation of moral judgment to opinions about public policies could not be explained as being due to piggybacking on education.

\section{Liberalism in the Two Churches}

From the reputations of the churches, we expected that the two congregations would differ on the ideological variables (FUNDA, THEO, and POLCON), moral judgment development (DIT), and opinions about public policy issues (ATHRI). Table 1 lists these variables and their differences between the church groups. All major independent and dependent variables were significantly different between the two churches in the expected directions (which, for convenience of discussion, we term the liberal or conservative direction of the variable, although in the introduction, we contend that all of these variables do not reduce to a single unitary construct of liberalism-conservatism). 
Table 1

Descriptive Statistics for the Samples

\begin{tabular}{|c|c|c|c|c|}
\hline \multirow[b]{2}{*}{ Variable } & \multicolumn{2}{|c|}{ Study 1: Church members } & \multirow{2}{*}{$\begin{array}{c}t \text {-test } \\
\text { difference }^{\mathbf{a}} \\
\end{array}$} & \multirow{2}{*}{$\begin{array}{l}\text { Study 2: } \\
\text { Students }\end{array}$} \\
\hline & Baptist & UCC & & \\
\hline \multicolumn{5}{|c|}{ Demographic variables } \\
\hline$n$ & 50 & 46 & & 62 \\
\hline Female/male & $31 / 19$ & $30 / 16$ & $n s$ & $38 / 24$ \\
\hline AGE & $46.69(14.60)$ & $48.33(17.05)$ & $n s$ & $23.42(3.39)$ \\
\hline ED1 & $4.62(1.17)$ & $3.76(1.66)$ & $2.90^{* *}$ & $4.24(1.91)$ \\
\hline $\mathrm{ED} 2$ & $5.09(1.05)$ & $4.45(1.43)$ & $2.34^{*}$ & $5.06(1.54)$ \\
\hline $\mathrm{OCCl}$ & $55.33(21.41)$ & $60.99(21.58)$ & 1.28 & $56.79(23.05)$ \\
\hline OCC2 & $47.16(12.16)$ & $53.96(12.38)$ & $2.55^{* *}$ & $50.34(14.78)$ \\
\hline \multicolumn{5}{|l|}{ Major variables } \\
\hline POLCON & $3.88 \quad(0.75)$ & $3.09(0.96)$ & $4.49 * * * * *$ & $2.85(0.94)$ \\
\hline FUNDA & $71.90 \quad(2.62)$ & $51.59(9.75)$ & $13.68 * * * * *$ & $55.48(14.78)$ \\
\hline THEO & $26.78(3.08)$ & $19.28(4.14)$ & $10.12 * * * * *$ & $19.18(7.87)$ \\
\hline DIT P score & $32.44(11.29)$ & $41.72(15.33)$ & $3.35^{* * * * *}$ & $48.58(15.13)$ \\
\hline DIT Stage 4 & $28.02(5.88)$ & $21.40(8.48)$ & $4.41 * * * * *$ & $16.31(7.57)$ \\
\hline ORTHO & $85.44 \quad(8.63)$ & $63.28(14.89)$ & $8.82 * * * * *$ & $60.58(17.84)$ \\
\hline ATHRI & $128.42(20.71)$ & $149.72(19.70)$ & $5.85^{* * * * * *}$ & $159.16(17.26)$ \\
\hline
\end{tabular}

Note. Standard deviations are in parentheses. ED1 = participant's level of education; ED2 = education of family's primary wage earner; $\mathrm{OCC} 1=$ participant's occupation; $\mathrm{OCC} 2=$ occupation of family's primary wage earner; POLCON = political conservatism; FUNDA = Brown and Lowe's (1951) fundamentalism score; THEO = Hoge's (1972) Intrinsic Religious Motivation Scale; ORTHO = regression equation built from POLCON, FUNDA, and Defining Issues Test (DIT) postconventional (P) score; ATHRI = Attitudes Toward Human Rights Inventory.

${ }^{a} t$-test difference is the independent $t$ test for differences between the Baptist and United Church of Christ (UCC) church members.

${ }^{*} p<.05 .{ }^{* *} p<.01 .{ }^{* * * * *} p<.001$.

Summary scores for each measure (means and standard deviations) are reported; although as suggested by the high internal consistencies of the ideology scales, each single item also tended to be significantly different between the congregations. Of the 15 items on the Inventory of Religious Belief (FUNDA), all were separately significantly different; of the 10 items on the Intrinsic Religious Motivation Scale (THEO), all were significantly different; and of the 40 items on the ATHRI, 23 were significantly different, the 10 platitude items being generally less discriminating (all participants tended to agree with the civil libertarian position). We note that the ATHRI item concerning euthanasia and the item concerning abortion are similar to the issues raised by Jensen (1996), and like Jensen, we also found significant differentiation between the congregations on these issues. Furthermore, Table 1 shows that a significant difference was found for self-reported liberal-conservative political identity (POLCON). Although there was some variance within the churches, overall the Baptists regarded themselves as more politically conservative than did the UCC members. In addition, the DIT was higher on postconventional thinking (P score) for the UCC congregation. In contrast, the Baptists had a higher mean score on Stage 4 (maintaining norms) thinking than did the UCC members.

In summary, we were successful in locating two congregations with polarized positions on public policy issues regarding human rights, and these polarities were found in ideological and moral judgment measures as well. Differences on all the measures (except education) were in the expected directions. We had sought to find the Orthodox-Progressive split where other researchers had found it (in contrasting churches), and we also found it.
Because the two congregations can be regarded as two subcultures, each with its own ideology, these data support the cultural ideology explanation that accounts for differences in views on public policy issues. That is, according to this view, as members are acculturated into each group, one can suppose that members are influenced by the values, interpretations, and practices of their respective groups. However, as one shall see, subcultural socialization is not the only determinant of people's opinions about public policy matters. Although there were striking differences between the groups, there was considerable within-group variation, suggesting that something else was codetermining people's opinions.

\section{Intercorrelations Among the Variables}

Table 2 shows the bivariate correlations between each of the variables (upper portion of Table 2). The correlational pattern was consistent in that the more liberal pole of each measure was positively linked to the more liberal pole of the other measures.

Looking more closely, note the correlations with ATHRI. Note that GROUP (belonging to the Baptist or the UCC church) was not the highest correlation with ATHRI. The DIT was higher. Using the procedure recommended by Howell (1987, pp. 244-245), with Fisher's $r$-to- $z$ transformations, the correlation of the DIT with ATHRI (.65) was significantly higher than that of GROUP with ATHRI (.52), $t(93)=2.54, p<.02$. This finding suggests that explaining the variance in opinions about public policy issues should include moral judgment. Also, the correlation of FUNDA with ATHRI (-.63) was significantly higher than that of GROUP with ATHRI, $t(93)=3.17, p=.01$. However, the correlation of 
Table 2

Correlations Between Variables in Study 1

\begin{tabular}{|c|c|c|c|c|c|c|c|c|c|}
\hline Variable & ATHRI & GROUP & POLCON & FUNDA & THEO & DIT & ORTHO & $\mathrm{OCCl}$ & ED1 \\
\hline \multicolumn{10}{|c|}{ Bivariate correlations } \\
\hline ATHRI & - & & & & & & & & \\
\hline GROUP & .52 & - & & & & & & & \\
\hline POLCON & -.58 & -.42 & - & & & & & & \\
\hline FUNDA & -.63 & -.83 & .44 & - & & & & & \\
\hline THEO & -.40 & -.72 & .30 & .80 & - & & & & \\
\hline DIT P score & .65 & .33 & -.47 & -.38 & -.16 & - & & & \\
\hline ORTHO & -.79 & -.68 & .73 & .80 & .55 & -.82 & - & & \\
\hline $\mathrm{OCCl}$ & .24 & .13 & -.07 & -.20 & -.08 & .22 & -.23 & - & \\
\hline ED1 & -.43 & -.29 & .40 & .38 & .20 & -.31 & .45 & -.48 & - \\
\hline
\end{tabular}

Partial correlations

\begin{tabular}{lll} 
GROUP & -.04 & Controlling for THEO, DIT, POLCON, FUNDA \\
DIT P score & $.47 * * * * *$ & Controlling for THEO, POLCON, FUNDA, GROUP \\
POLCON & $-.29 * * * * *$ & Controlling for THEO, FUNDA, GROUP, DIT \\
FUNDA & $-.34 * * * *$ & Controlling for THEO, GROUP, DIT, POLCON \\
THEO & -.08 & Controlling for GROUP, DIT, POLCON, FUNDA \\
\hline
\end{tabular}

Note. Probability levels for the bivariate correlations are as follows: .26 is significant at $p<.01$, and .20 is significant at $\dot{p}<.05$ with $96 d f$. ATHRI = Attitudes Toward Human Rights Inventory; GROUP $=$ church membership ( 1 = Baptist, 2 = United Church of Christ); POLCON = political conservatism; FUNDA = Brown and Lowe's (1951) fundamentalism score; THEO = Hoge's (1972) Intrinsic Religious Motivation Scale; ORTHO = regression equation built from POLCON, FUNDA, and Defining Issues Test (DIT) postconventional (P) score; OCCl = participant's occupation; ED1 = participant's level of education. $* * * * p<.005$. $* * * * * p<.001$.

POLCON with ATHRI (-.58) was not significantly stronger than that for GROUP with ATHRI. In sum, group membership accounted for only about $27 \%$ of the variance in ATHRI $(r=.52)$. Something else accounted for the other $73 \%$.

Table 2 also indicates that the two congregations did not differ much on education or occupation (note that the correlations of occupation and education with GROUP were in the .10 s and $.20 \mathrm{~s}$ ). The findings of this study do not challenge the often-repeated finding in the literature of a significant positive relation between education, occupation, and liberal political attitudes because the design of the study was to control these variables and not to study the correlation of education or occupation as it exists in the natural social environment.

Another view of the relationships of the variables with ATHRI comes from partial correlations (given in the bottom portion of Table 2, rather than bivariate correlations, given in the top portion of Table 2) of each variable after controlling for the other variables. One can see that the partial correlation of GROUP with ATHRI (after controlling for the religious and political ideology variables and for the DIT) was negligible. In contrast, the partial correlation with moral judgment (DIT P score) was substantial and statistically significant. (The partial correlation of Fundamentalism and liberalism-conservatism was also significant.) The analysis of partial correlations corroborates the pattern discussed in the bivariate correlations: The most powerful contributions to the predictability of public policy issues (ATHRI) were from the DIT P score, religious Fundamentalism, and political liberalism-conservatism.

\section{Measuring the Psychological Construct of Orthodoxy-Progressivism}

Thus far, we have found that there was a difference between the two churches on liberalism-conservatism, as measured in various ways. Also, we had reason to believe that the combined sample of both churches represented a fairly large portion of the range of our measures. Consider the following: We were not limited in our analysis to explaining the variance of ATHRI to simply the classification of participants by church membership. If we attended to the individually measured variables (ideology subdivided into FUNDA, THEO, and POLCON) plus individual development in moral judgment (DIT), we could include both the cultural ideology explanation and the moral judgment explanation in accounting for variation on public policy issues. In other words, this second approach allowed us to go beyond church membership and allowed us to consider combining cultural ideology with moral judgment. The combination of variables was our operationalization of the construct of Orthodoxy-Progressivism (ORTHO).

To test the combination of the independent variables in predicting to the dependent variable, we ran a multiple regression on the two church samples $(N=96)$. The independent variables were POLCON, FUNDA, THEO, and DIT; ATHRI was the dependent variable. The multiple regression correlation was .79 , accounting for $62 \%$ of the variance on the ATHRI. Thus, the combined measure of individual measures accounted for more than twice the variance $(62 \%)$ on the ATHRI than did church membership alone $(27 \%){ }^{3}$ THEO (i.e., theocentrism on the Intrinsic Religious Mo-

\footnotetext{
${ }^{3}$ Because GROUP was a binary variable and the other variables were not (they had many values, not just two), this raised the question of whether we biased the data against GROUP. There are several considerations for why we do not think this explains the difference between church membership explaining $27 \%$ of the variance and ORTHO explaining 62\%: (a) Using two extreme groups to represent the effects of church membership might actually have increased the effects of group membership instead of decreasing it. The use of middle values (as in the DIT and ORTHO) would
} 
Table 3

Summaries of Multiple Regressions for Studies 1 and 2, Predicting to Opinions on Public Policy Issues (ATHRI)

\begin{tabular}{|c|c|c|c|c|}
\hline Variable & $B$ & $S E B$ & $\beta$ & $t$ \\
\hline \multicolumn{5}{|c|}{ Study $1(N=96)$} \\
\hline DIT P score & 0.59 & 0.11 & .40 & $5.38 * * * * *$ \\
\hline FUNDA & -0.63 & 0.12 & -.38 & $-5.14 * * * * *$ \\
\hline POLCON & -4.92 & 1.69 & -.22 & $-2.92 * * * *$ \\
\hline \multicolumn{5}{|c|}{ Study $2(N=62)$} \\
\hline DIT P score & 0.31 & 0.09 & .27 & $3.31 * * * *$ \\
\hline FUNDA & -0.29 & 0.10 & -.25 & $-2.88 * * *$ \\
\hline POLCON & -9.59 & 1.56 & -.52 & $-6.13 * * * * *$ \\
\hline
\end{tabular}

Note. ATHRI $=$ Attitudes Toward Human Rights Inventory; DIT $=$ Defining Issues Test; $\mathrm{P}=$ postconventional; FUNDA $=$ Brown and Lowe's (1951) fundamentalism score; POLCON = political conservatism. ${ }^{* * *} p<.006 .{ }^{* * * *} p<.005 .{ }^{* * * * *} p<.001$.

tivation Scale) was not significantly related to ATHRI in multiple regression with the other variables. The redundancy of THEO was also suggested in the partial correlation analysis. In other words, in this sample, variation on THEO did not contribute unique variance related to attitudes about public policy after its shared variance with the other variables was partialed out. Therefore, we ran another multiple regression without THEO: with POLCON, FUNDA, and DIT predicting to ATHRI. Table 3 (top portion) summarizes this multiple regression (involving only minor shifts in values from the original regression that included THEO).

Table 3 shows that combining moral judgment development with political and religious ideology predicted powerfully to human rights issues $(R=.79)$. Reversing the signs in the regression equation so that the measure could be called "Orthodoxy" (so as to negatively correlate with ATHRI), we had a variable that was a combination of moral, political, and religious variables, labeled ORTHO. ORTHO was formed by taking the following values from the regression analysis: 4.92 (POLCON) +.63 (FUNDA) +-.59 (DIT). Note that in Table 3, moral judgment has a large standardized beta weight relative to the three predictors, indicating that the developmental variable, moral judgment, should be included in predicting to ATHRI (see Figure 1).

\section{Study 2: Student Sample}

There are several problems in knowing what generalizations follow from Study 1. First, the two congregations were specifically selected for the likelihood of representing polar opposites on the construct of Orthodoxy-Progressivism. But extreme groups on a construct do not always predict how samples will behave that are not selected for their

be penalized if the middle values of the dependent variables were not equally spaced in strict conformity to the linear model. Therefore, more values may have been a liability. (b) In Sample 2, when church denomination was used to indicate group membership (and there were many values, not just two), the variance accounted for was very minimal. Therefore, group membership was not necessarily higher when not a binary variable. (c) There was considerable within-group variation on all of the variables, including the dependent variable, ATHRI. This within-group variance is consistent with that in Jensen (1996). extreme views. Second, the formula for ORTHO predicted very well to ATHRI for the sample in Study 1. But the formula was based on a multiple regression based on that sample's data and therefore may have capitalized on chance factors in that particular data set. To claim some generality, the formula and findings need to be replicated with another sample. Third, multiple regression is a statistical procedure designed so that many independent variables predict better to the dependent variable than does one independent variable alone. Therefore, how does one know that finding that a multiple regression predicts better to ATHRI than to the church membership variable does not simply represent the success of the workings of the statistical procedure of multiple regression rather than an insight particular to moral thinking? Fourth, what is true of a sectarian sample (i.e., the church sample) may not be true of a secular sample (people not recruited from churches). Study 2 was designed to address these problems.

As a cross-replication of Study 1, Study 2 tested a sample of university students. They differed from the church sample in several ways. First, the student sample was younger (mean age $=23$ years) and at the beginning of their careers, whereas the church members were older (mean age $=47$ years) and well along in their careers. Second, the students were in a setting designed to foster critical thinking and questioning of roles and practices, whereas the church members were established in their roles and were responsible for maintaining families, jobs, and communities. Furthermore, the university was located in a community with many church-based 4-year colleges, so we assumed that highly religious young people were not at the secular institution. In addition, the college years are noted for their questioning of religion (Pascarella \& Terenzini, 1991). Thus, the sample in Study 2 seemed apt for testing the robustness of the Orthodoxy construct and addressed the concerns of the first, third, and fourth problems listed above. Furthermore, using the same formula in Study 2 as that for ORTHO derived from the regression in Study 1 provided a check on chance factors in building up the multiple correlation in Study 1 (thus addressing the second problem given above).

\section{Method}

\section{Participants}

Eighty-two undergraduates from a public university volunteered to complete the questionnaires. Sixty-two undergraduates had completed protocols for every measure and passed consistency checks on the DIT. Descriptive demographic data are listed in Table 1 . The 56 undergraduates who identified themselves as religious were affiliated with the Christian faith; therefore, the FUNDA and THEO measures were appropriate. Six of the undergraduates listed no religious affiliation. The range of education was restricted (to only undergraduates) so that education could be controlled as a possible confound (for similar reasons to those in Study 1).

\section{Materials and Procedure}

The same measures were used as in the first study. The questionnaires were delivered by hand to the students. As in the first study, questionnaires were ordered randomly for each participant.

\section{Results and Discussion}

Table 1 shows the means and standard deviations for the primary variables. In general, the student sample was more like the 


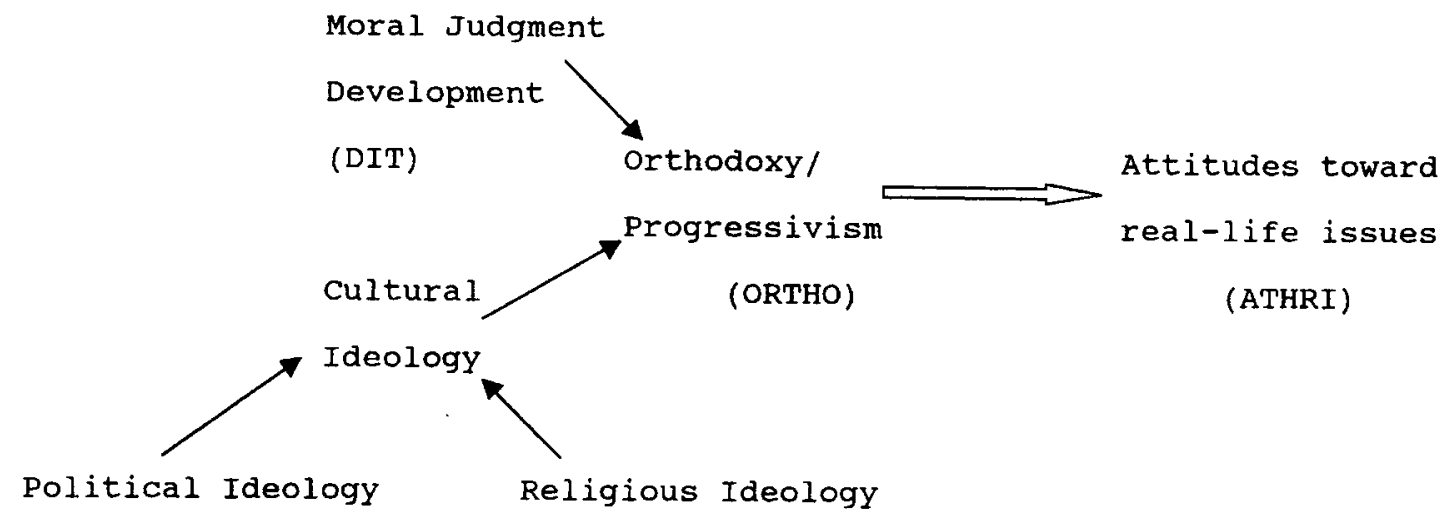

(POLCON)

(FUNDA)

Figure 1. The components of moral thinking and the variables we used. DIT $=$ Defining Issues Test; ATHRI $=$ Attitudes Toward Human Rights Inventory; POLCON = political conservatism; FUNDA = fundamentalism.

UCC sample than the Baptist sample: more liberal on political conservatism (POLCON), theocentrism (THEO), fundamentalism (FUNDA), Orthodoxy (ORTHO), moral judgment (DIT P score), and ATHRI. However, the main point for Study 2 was not to compare mean scores with other samples (and thus to represent the population of students in contrast to church populations) but to investigate relations among the variables.

As in Sample 1, we ran a multiple regression on Sample 2 with POLCON, FUNDA, THEO, and DIT P score as the independent variables and ATHRI as the dependent variable. As in Study 1, the THEO variable did not have significant unique predictability to ATHRI. Therefore, we ran a second multiple regression, summarized in Table 3 (bottom portion). The multiple correlation was .82, accounting for $68 \%$ of the variance in ATHRI. As in Study 1 , the three independent variables each had statistically significant beta weights, indicating again that each variable did not reduce to the other but in combination produced a powerful association with ATHRI.

The specific values for the beta weights for the independent variables in Sample 2 differed somewhat from the beta weights in Sample 1 (in Table 3, compare the top portion with the bottom portion). Because there was some specificity in the values of the parameters relative to the sample, we wanted some test of the generality and stability of the multiple regression results of Study 1. To do this, we used the beta values derived in Study 1 for ORTHO and applied them to the data in Study 2. Therefore, the correlation between ORTHO and ATHRI in Study 2 was not due to the workings of a particular statistical procedure that maximized the association of variables within the particular data set of Study 1. In Study 2, the correlation of ORTHO with ATHRI was -.77 , accounting for $59 \%$ of the variance (still more than twice the variance accounted for by church membership, $27 \%$ ). There was a little shrinkage in the correlation of Study $2(.77)$ with the multiple correlation of Study $1(.79)$, perhaps representing the effects of capitalizing on chance factors in Study 1. Perhaps a better estimate of the shrinkage due to sample specificity would be to compare .77 with .82 (the sample-specific multiple regression of Study 2). But in either case, the shrinkage was slight, and the variance accounted for was substantial, supporting the generality of the results of Study 1.

\section{The Significance of Dropping Out the Theocentrism Variable}

There are both theoretical and methodological implications to the fact that the theocentrism variable (i.e., THEO on the Intrinsic Religious Motivation Scale) dropped out of the multiple regression both in Study 1 and Study 2. First, regarding the theoretical implication, one might initially think that theocentrism should be related to ORTHO (as we originally did-that was why we included it in the test). Also, according to the approach of Shweder, Much, Mahapatra, and Park (1997), who proposed analyzing moral thinking into the discourse of autonomy, community, and divinity, we expected a significant role to be played by the theocentrism variable. According to this line of theorizing, a person high on theocentrism would be expected to spontaneously invoke expressions concerning religion in making social-political decisions (i.e., we expected the person would use the discourse of divinity rather than the discourse of autonomy or community). Shweder et al.'s formulation attributes great importance to a person's choosing to speak in religious terms rather than in nonreligious discourse. But the analyses of Study 1 and Study 2 suggest that simply harkening to religion (of any kind) does not make a significant difference in explaining opinions about public policy issues; what matters is whether the underlying understanding of religion is fundamentalist or not. (FUNDA is significant, but THEO is not.)

A second implication that is methodological follows from eliminating theocentrism from the composite variable, ORTHO. Although the simple bivariate correlation of theocentrism with ATHRI was significant, its elimination from the multiple regression showed that ORTHO was not simply an aggregate of whatever variables happened to correlate with ATHRI. It is not the case that more independent variables are invariably better than fewer variables. The multiple regression results are not the inevitable outcome of a statistical procedure that ensures that more variables (no matter what they are) produce higher multiple correlations than fewer variables. THEO showed this-its inclusion did not improve the multiple correlation. In fact, we tested the idea of seeing whether including 10 predictor variables would improve the multiple correlation but found that adding variables ( 7 more than the standard 3) did not increase the correlation. Therefore, our result 


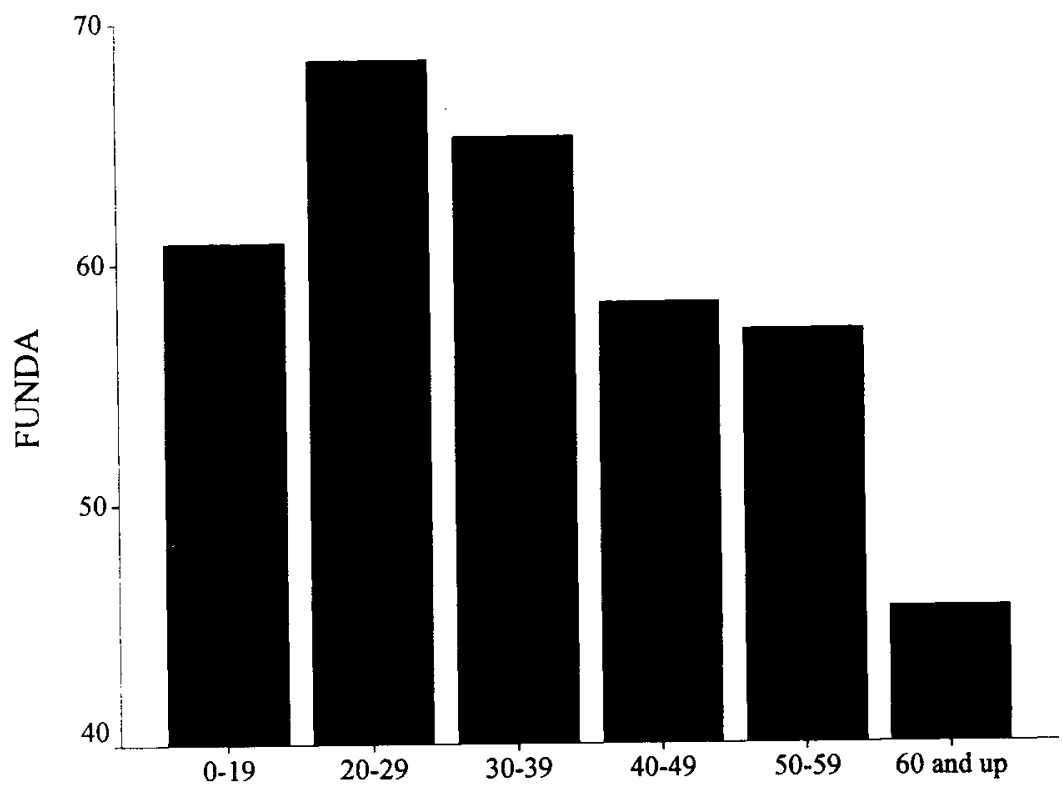

Grouped by DIT P Score

Figure 2. Fundamentalism (FUNDA) means by postconventional (P) moral judgment score group. DIT = Defining Issues Test.

was not simply a matter of adding more independent variables to the regression that accounted for the strength of 3 variables predicting to ATHRI. There was a special relationship among the 3 variables that predicted to ATHRI. It is not just that there are 3 , but the particular 3 is significant.

\section{Fundamentalism and Moral Judgment}

Fundamentalism (i.e., FUNDA from the Inventory of Religious Belief) had a special relation to moral judgment. One can see in Figure 2 the relation between development on the DIT-in terms of the usual index, the $\mathrm{P}$ score-and Fundamentalism when all participants from both Study 1 and Study 2 were used. On the $x$ axis, $P$ scores are grouped into six groups, from low $(P=0-19)$ to high ( $\mathrm{P}=60$ and up). On the $y$ axis are plotted the average FUNDA scores for each group. With development in moral judgment, FUNDA at first increased and then decreased. This gives new meaning to the phrase "middle America." This phrase is customarily used to refer to the middle class of Americans (in terms of socioeconomic status), who are more politically conservative than either the lower or the higher socioeconomic class and in terms of their law-and-order orientation. Here, the term middle refers to the midranges of moral judgment development in which religious fundamentalism is highest.

The curvilinear relation of Fundamentalism with moral judgment was also detectable in the bivariate correlations of FUNDA with Stage 4 on the DIT (in contrast to P). Whereas the correlation of FUNDA with $P$ was -.44 , the correlation with Stage 4 on the DIT was .51. In this case, the Stage 4 correlation with FUNDA was significantly higher than that with $\mathrm{P}, t(155)=8.62, p<.001$. Although $P$ usually has higher correlations than Stage 4 in DIT studies, the attenuation of P's correlation was probably due to P's curvilinear relation with FUNDA, whereas the relation of FUNDA with Stage 4 was more linear. And so the rise of Stage 4 is linked to higher scores on FUNDA. This indicates that those with high fundamentalism scores (who endorsed religious items, for instance those dealing with Jesus's virgin birth and the physical second coming of Christ) also highly endorsed secular Stage 4 items on the DIT concerning uniform respect for civil rules and punishments, citizen duties, property rights, and students' respect for university authorities (e.g., "Wouldn't it be a citizen's duty to report an escaped criminal, regardless of the circumstances?" and "Every time someone escapes punishment for a crime, doesn't that just encourage more crime?"). This finding suggests speculation about the formation of the Orthodox worldview and suggests more generally how individual development in moral judgment might be related to cultural ideology.

\section{General Discussion}

The major empirical findings of the present study are as follows: (a) Political identity as liberal or conservative, religious fundamentalism, moral judgment, and views on public policy issues (those especially relevant to civil libertarianism) were all significantly intercorrelated, liberal views going with other liberal views and conservative views going with other conservative views. Church congregations with the general reputation for their conservative or liberal views also showed significant differences on these variables. (b) Despite significant bivariate correlations, each of these variables-POLCON, FUNDA, and DIT-could not be reduced to each other or to a common factor of liberalism-conservatism. Each variable had unique information in predicting to public 
policy issues (as shown in multiple regressions and in partial correlations). (c) Political identity (POLCON), religious fundamentalism (FUNDA), and moral judgment (DIT P score) could be combined to predict over $60 \%$ of the variance in views on public policy issues (e.g., issues dealing with abortion, free speech, rights of the accused, women's roles, and the role of religion in public education). Church membership predicted less than half of that variance. (d) Fundamentalism and Stage 4 (on the DIT) were significantly correlated $(r=.51)$.

Although statistical procedures such as multiple regression allow us to combine any variable with any other variable, what theoretical sense does it make to combine the individual cognitive variable of moral judgment development (DIT) with cultural ideology variables (POLCON and FUNDA)? Some theorists (e.g., Emler et al., 1983; Shweder, 1982) suggest that the Kohlbergian scheme of moral judgment is really liberalism bias masquerading as cognitive development; in this view, combining both DIT and measures of liberalism-conservatism does not make much theoretical sense in that the measures are redundant. In contrast, Piaget (1932/1965) and Kohlberg (1984) suggested that the autonomous and heteronomous aspects of moral thinking operate sequentially, one process in ascendancy at one time. In contrast, our view of moral thinking is inspired by the model of Kintsch and van Dijk (1978) that portrays reading comprehension as the result of two processes acting in parallel-simultaneously and dialectically. (Although we did not depict the two processes of moral thinking as the same two processes described in Kintsch and van Dijk's model of reading comprehension, the simarility is in the idea of two parallel processes influencing each other to produce a cognitive product.)

The focus of this study on Orthodoxy-Progressivism is consistent with a view of moral thinking as involving autonomous and heteronomous processes in parallel. Our speculation goes something like this: The formation of Orthodox moral thinking is especially likely as the moral judgment process is developing the schema of maintaining norms (Stage 4 in Kohlberg's terms). Then the person recognizes the need for social norms to stabilize and establish order. The person is especially drawn to religious fundamentalism, which provides clear norms and strong authorities. Hence, moral judgment can supply the conceptual bedrock (the epistemological concepts) for an ideology. Simultaneously, if the person is exposed to and reinforced with religious fundamentalism, strong religious authority transfers to strong respect for civil authorities (e.g., the regard for religious authorities transfers to school principals, judges, and university presidents-the civil authorities in DIT dilemmas). Thus, religious authoritarianism can lead to high Stage 4 scores on the DIT. Furthermore, if religious fundamentalism regards the questioning of its authority as beyond human scrutiny, forbidden to inquiry and debate, then the person is blocked from progression into postconventional thinking, which is based on open scrutiny and debate. Therefore, in Orthodoxy, we have an example of moral judgment influencing cultural ideology, and vice versa. We are not suggesting that with time people change from Orthodoxy to Progressivism, nor are we suggesting that conservatives are retarded liberals. Instead, we are suggesting an example of autonomous processes interacting with heteronomous processes to produce moral thinking. An important qualification should be mentioned here. We do not suppose that the only route to political conservatism is by means of religious fundamentalism-
Stage 4 thinking and Orthodoxy. Although both the DIT and FUNDA are significantly correlated with ATHRI, it is nevertheless true that political ideology has unique predictability to ATHRI. In other words, people may take a conservative stance on human rights but do not have fundamentalist beliefs or high Stage 4 scores-they are political conservatives for other reasons (other than the explanation we have been advancing concerning fundamentalism-Stage 4-Orthodoxy). The main point of this article, however, is that moral judgment, religious fundamentalism, and political identity each have unique information and are not reducible to each other, and when they are combined, they produce powerful predictions to moral thinking about important public policy issues.

\section{References}

Allport, G. W., \& Ross, J. M. (1967). Personal religious orientation and prejudice. Journal of Personality and Social Psychology, 5, 432-443.

Brown, D. G., \& Lowe, W. L. (1951). Religious beliefs and personality characteristics of college students. Journal of Social Psychology, 33, 103-129.

Emler, N., Resnick, S., \& Malone, B. (1983). The relationship between moral reasoning and political orientation. Journal of Personality and Social Psychology, 45, 1073-1080.

Ernsberger, D., \& Manaster, G. (1981). Moral development, intrinsic/ extrinsic religious orientation and denominational teachings. Genetic Psychology Monographs, 104, 23-41.

Getz, I. (1984). Moral judgment and religion: A review of the literature. Counseling and Values, 28, 94-116.

Getz, I. (1985). Moral reasoning, religion, and attitudes toward human rights. Unpublished doctoral dissertation, University of Minnesota, Twin Cities Campus.

Gross, P. R., \& Levitt, N. (1994). Higher superstition. Baltimore: Johns Hopkins University Press.

Haan, N., Smith, B., \& Block, J. (1968). The moral reasoning of young adults. Journal of Personality and Social Psychology, 10, 183-201.

Haug, M. R. (1977). Measurement in social stratification. Annual Review of Sociology, 3, 51-77.

Hoge, D. R. (1972). A validated intrinsic religious motivation scale. Journal for the Scientific Study of Religion, 11, 369-376.

Howell, D. C. (1987). Statistical methods for psychology (2nd ed.). Boston: Duxbury.

Hunter, J. D. (1991). Culture wars: The struggle to define America. New York: Basic Books.

Jelen, T. G. (Ed.). (1989). Religions and political behavior in the United States. New York: Praeger.

Jelen, T. G. (1991). The political mobilization of religious beliefs. New York: Praeger.

Jensen, L. A. (1996). Different habits, different hearts: Orthodoxy and Progressivism in the United States and India. Unpublished doctoral dissertation, University of Chicago.

Jensen, L. A. (1997). Culture wars: American moral divisions across the adult lifespan. Journal of Adult Development, 4, 107-121.

Kintsch, W., \& van Dijk, T. A. (1978). Toward a model of text comprehension and production. Psychological Review, 85, 363-394.

Kohlberg, L. (1969). Stage and sequence: The cognitive developmental approach to socialization. In D. A. Goslin (Ed.), Handbook of socialization theory (pp. 347-480). Chicago: Rand McNally.

Kohlberg, L. (1981). Essays on moral development: Vol. I. The philosophy of moral development. San Francisco: Harper \& Row.

Kohlberg, L. (1984). Essays on moral development: Vol. 2. The psychology of moral development. San Francisco: Harper \& Row.

Marty, M. E., \& Appleby, R. S. (1993). Fundamentalism and the State. Chicago: University of Chicago Press. 
McClosky, H., \& Brill, A. (1983). Dimensions of tolerance. New York: Russell Sage Foundation.

Pascarella, E. T., \& Terenzini, P. (1991). How college affects students: Findings and insights from twenty years of research. San Francisco: Jossey-Bass.

Piaget, J. (1965). The moral judgment of the child (M. Gabain, Trans.). New York: Free Press. (Original work published 1932)

Rawls, J. (1993). Political liberalism. New York: Columbia University Press.

Reiss, A. J. (1961). Occupations and social status. New York: Free Press. Rest, J. R. (1979). Development in judging moral issues. Minneapolis: University of Minnesota Press.

Rest, J., Narvaez, D., Bebeau, M., \& Thoma, S. (1999). Postconventional thinking: A neo-Kohlbergian approach. Mahwah, NJ: Erlbaum.

Rest, J. R., Thoma, S. J., \& Edwards, L. (1997). Designing and validating a measure of moral judgment: Stage preference and stage consistency approaches. Journal of Educational Psychology, 89, 5-28.
Rest, J., Thoma, S. J., Narvaez, D., \& Bebeau, M. J. (1997). Alchemy and beyond: Indexing the Defining Issues Test. Journal of Educational Psychology, 89, 498-507.

Sandel, M. (1982). Liberalism and the limits of justice. Cambridge, England: Cambridge University Press.

Shweder, R. A. (1982). Liberalism as destiny. Contemporary Psychology, $27,421-424$.

Shweder, R. A., Much, N. C., Mahapatra, M., \& Park, L. (1997). The "big three" of morality (autonomy, community, divinity) and the "big three" explanations of suffering. In A. Brandt \& P. Rozin (Eds.), Morality and health. New York: Routledge.

Walzer, M. (1983). Spheres of justice. New York: Basic Books.

Received August 12, 1997

Revision received June 14, 1998

Accepted June 14, 1998 